\title{
HBV promotes the proliferation of hepatic stellate cells via the PDGF-B/PDGFR- $\beta$ signaling pathway in vitro
}

\author{
QIXUAN BAI ${ }^{1}$, JING AN $^{2}$, XIAONING WU ${ }^{1}$, HONG YOU $^{1}$, HONG MA $^{1}$, \\ TIANHUI LIU ${ }^{1}$, NA GAO ${ }^{2}$ and JIDONG JIA ${ }^{1}$ \\ ${ }^{1}$ Liver Research Center, Beijing Friendship Hospital, Capital Medical University, ${ }^{2}$ Department of Microbiology, \\ School of Basic Medical Sciences, Capital Medical University, Beijing, P.R. China
}

Received April 25, 2012; Accepted July 10, 2012

DOI: $10.3892 /$ ijmm.2012.1148

\begin{abstract}
The activation of hepatic stellate cells (HSCs) is closely associated with liver fibrosis in chronic hepatitis B virus (HBV) infection. However, the molecular mechanisms leading to HSC activation remain unclear. It has been reported that the platelet-derived growth factor-B (PDGF-B)/PDGF receptor- $\beta$ (PDGFR- $\beta$ ) signaling pathway is involved in this process. Thus, we investigated whether HBV and its protein contribute to HSC proliferation by the PDGF-B/PDGFR- $\beta$ signaling pathway. HBV particles were purified from the supernatant of HepG2.2.15 cells by ultracentrifugation and the cell lines carrying HBV preS, e, c or x genes were obtained. After incubation with HBV particles or co-cultured with the cell lines expressed in the viral protein, the proliferation of LX-2 cells, an HSC cell line, were detected by flow cytometry and real-time PCR and the expression of molecules related to the PDGF-B/PDGFR- $\beta$ signaling pathway were further measured. Our results indicated that $\mathrm{HBV}$ particles, $\mathrm{c}$ and $\mathrm{x}$ proteins promoted LX-2 proliferation and increased the mRNA levels of PDGF-B, PDGFR- $\beta$, collagen-I and $\alpha$-smooth muscle actin ( $\alpha$-SMA), as well as the phosphorylation of PDGFR- $\beta$; however, the expression protein levels of PDGF-B and PDGFR- $\beta$ remained unchanged. In conclusion, $\mathrm{HBV}$ particles and $\mathrm{HBV} \mathrm{c}$ and $\mathrm{x}$ proteins promote HSC proliferation and fibrogenesis in vitro and the PDGF-B/PDGFR- $\beta$ signaling pathway is important in this process.
\end{abstract}

Correspondence to: Professor Jidong Jia, Liver Research Center, Beijing Friendship Hospital, Capital Medical University, 95 Yong-an Road, Xicheng, Beijing 100050, P.R. China

E-mail: jiamd@263.net

Abbreviations: HBV, hepatitis B virus; HSCs, hepatic stellate cells; PDGF, platelet-derived growth factor; PDGFR- $\beta$, platelet-derived growth factor receptor- $\beta$; $\alpha$-SMA, $\alpha$-smooth muscle actin; GAPDH, glyceraldehyde phosphate dehydrogenase

Key words: hepatitis B virus, hepatic stellate cells, liver fibrosis, platelet-derived growth factor

\section{Introduction}

Liver fibrosis, resulting from chronic damage to the liver, is the progressive accumulation of fibrillar extracellular matrix (ECM) in the liver which eventually leads to cirrhosis and liver failure. Generally, the main causes of liver fibrosis include alcohol abuse, nonalcoholic steatohepatitis (NASH) and especially, the chronic hepatitis virus infection, such as hepatitis $\mathrm{B}$ virus (HBV) and $\mathrm{C}(\mathrm{HCV})(1)$. The progression of fibrosis is a dynamic process where a potential population of fibrogenic cells in the liver, such as portal fibroblasts, mesenchymal cells derived from the bone marrow, hepatocytes and biliary epithelial cells are involved. Hepatic stellate cells (HSCs), the most important contributor cell type, are the main ECM-producing cells in liver fibrosis following activation into fibrogenic myofibroblast-like cells. Activated HSCs express many ECM proteins, including collagen, $\alpha$-smooth muscle actin ( $\alpha$-SMA), transforming growth factor- $\beta$ (TGF- $\beta$ ), matrix metalloproteinase (MMP) and tissue inhibitors of metalloproteinases (TIMP), which all contribute to liver fibrosis.

The activation of HSCs is regulated by several cytokines and growth factors. The platelet-derived growth factor-B (PDGF-BB) is the most prominent factor in HSCs proliferation and liver fibrosis development (2). Generally, PDGF-BB exerts its effects by binding to its receptor (PDGFR- $\beta$ ), inducing receptor dimerization and tyrosine-autophosphorylation. The activated phosphorylated receptor recruits the signal transduction molecules, initiating various intracellular signaling pathways (3-5). Recently, the expression of PDGF-BB and its receptor (PDGFR- $\beta$ ) has been shown to be increased in both experimental fibrosis in rats and human fibrotic liver $(6,7)$, with a weak expression presented in the normal liver. Moreover, HSCs may perpetuate their proliferative status by active secretion of PDGF in a paracrine or autocrine manner (8). Mechanisms regulating the PDGF-B/PDGFR- $\beta$ signal transduction have recently begun to be elucidated $(9,10)$.

According to current clinical studies, chronic HBV infection is strongly associated with the development of fibrosis, cirrhosis and hepatocellular carcinoma (HCC), which may be caused by the interaction between HBV or the viral proteins and HSCs, directly, or indirectly. There is increasing evidence that the intrahepatic accumulation of the HBV encoded $\mathrm{x}$ antigen $(\mathrm{HBx} \mathrm{Ag})$ correlates with the severity of chronic liver 
disease (CLD), as well as with the development of fibrosis and cirrhosis $(11,12)$. Certain studies also reported that the x protein expression in hepatocytes leads to paracrine activation and proliferation of HSCs (13). However, the possible role of the $\mathrm{x}$ protein and other viral proteins in the development of liver fibrosis, remains unknown. Thus, the role of HBV proteins in the process of liver fibrosis needs to be explored intensively. Moreover, according to several clinical data, the expression of PDGF-BB in liver tissues or serum level in chronic HBV patients reflects the degree of liver damage and the degree of hepatic fibrosis (14-16). There may be some type of correlation between the HBV viral proteins and the PDGF-B/PDGFR- $\beta$ signaling pathway, which may lead to the activation of HSCs.

Therefore, the aim of the present study was to observe the effect of $\mathrm{HBV}$ and its antigen components on the proliferation of HSCs and the expression of PDGF-BB and PDGFR- $\beta$, in order to clarify whether HBV or virus gene products are able to promote HSCs proliferation through PDGF-B/PDGFR- $\beta$ signaling pathway and further broaden our understanding of hepatic fibrogenesis.

\section{Materials and methods}

Purification of $H B V$ Dane particles by sucrose density gradient ultracentrifugation. Aliquots (6 ml) of 10, 20, 30, $40,50,60 \%(\mathrm{w} / \mathrm{w})$ sucrose in a solution containing $120 \mathrm{mM}$ $\mathrm{NaCl}, 12 \mathrm{mM}$ Tris $\cdot \mathrm{HCl}, 1 \mathrm{mM}$ EDTA $\cdot \mathrm{Na}_{2}(\mathrm{pH}$ 8.0) were carefully layered in a 40-ml ultracentrifuged tube and left at room temperature for $6 \mathrm{~h}$. Concentrated supernatant of HepG2.2.15, $4 \mathrm{ml}$, was layered on the sucrose gradient mentioned above, and ultracentrifugation was performed at $120,000 \times \mathrm{g}$ for $24 \mathrm{~h}$ at $4^{\circ} \mathrm{C}$ with the Beckman SW32Ti Rotor. Finally, the density of 43.5 to $44.5 \%$ sucrose fraction was collected, and a number of HBV Dane particles collected at this density were confirmed by electron micrographs (17). The concentrated HBV was then resuspended in fetal bovine serum (FBS) and stored at $-80^{\circ} \mathrm{C}$ until use. The copies of HBV were determined by real-time PCR.

Plasmid construction. The fragments of HBV preS, e, c and $\mathrm{x}$, obtained by PCR from the pHBV1.2 (complete genome of HBV isolate 57-1 subtype adw, a kind gift by Professor Lai Wei, Peking University, and the GenBank accession number AY518556.1) (18) respectively, were subcloned into the efficient vector, pCAGGSP7, containing the $\beta$-actin promoter (19). The positive clones were named $\mathrm{pHBV}-\mathrm{S}, \mathrm{pHBV}-\mathrm{E}, \mathrm{pHBV}-\mathrm{C}$ and pHBV-X, respectively. DNA sequencing was used to verify the plasmids, and the expression of these plasmids was further confirmed by indirect immunofluorescence in Vero cells.

Cell culture and transfection. The human hepatocellular carcinoma cell line HepG2 and the human HSC line LX-2 were grown in Dulbecco's modified Eagle's medium (DMEM, with $2 \mathrm{mM}$ glutamine, $10 \%$ (FBS), $100 \mathrm{U} / 1$ penicillin and $100 \mu \mathrm{g} / \mathrm{ml}$ streptomycin) at $37^{\circ} \mathrm{C}$ in a $5 \% \mathrm{CO}_{2}$ incubator. HepG2.2.15, an HBV (serotype ayw, genotype D) stably transfected cell line, was also maintained in $10 \%$ FBS DMEM supplemented with $200 \mu \mathrm{g} / \mathrm{ml} \mathrm{G} 418$ (Sigma).

To express the 4 kinds of HBV proteins, HepG 2 cells were transfected with the plasmid of pHBV-S, pHBV-E, pHBV-C,
pHBV-X and pCAGGSP7 (as the control), respectively, using FuGENE HD transfection reagent (Roche), following the manufacturer's instructions. The cells were cultured with DMEM containing 10\% FBS and $600 \mu \mathrm{g} / \mathrm{ml}$ of G418 (Sigma). After selection, single cell clones stably transfected with the plasmids mentioned above were obtained, and named HepG-s, HepG-e, HepG-c, HepG-x and HepG-control, respectively. The expression of viral protein was evaluated by western blotting.

In vitro co-culture system. To elucidate the relationship between $\mathrm{HBV}$ proteins and liver fibrosis, an in vitro co-culture system of HepG-s, HepG-e, HepG-c, HepG-x, HepG2.2.15 and HepG-control cells with LX-2 cells was established according to a previous method with certain modifications (20). In the cell-to-cell non-contacted co-culture system, the cell line, which stably expressed the viral protein, was separated from LX-2 cells using a $0.4 \mu \mathrm{m}$ transwell membrane (Corning). Briefly, the same number of HepG-s, HepG-e, HepG-c, HepG-x, HepG2.2.15 and HepG-control cells (as a negative control) were plated into the upper chamber of a transwell insert. The same numbers of LX-2 cells were plated on the lower chamber. After $24 \mathrm{~h}$ co-culture in DMEM supplemented with $10 \%$ FBS, the confluence was achieved. The LX-2 cells were washed with phosphate-buffered saline (PBS) and co-cultured for another $24 \mathrm{~h}$ in serum-free DMEM. Finally, the LX-2 cells and supernatants were collected for the following experiments.

Detection of LX-2 cells proliferation by flow cytometry. In order to detect the LX-2 cell proliferation, 2 measures were employed: i) LX-2 cells were co-cultured with the stable transfected cell line, respectively, for $48 \mathrm{~h}$ as described above. ii) LX-2 cells were cultured in complete medium for $24 \mathrm{~h}$, serumstarved for $16 \mathrm{~h}$ and were then added the series of diluted concentrations of HBV (final concentration of HBV of each well was $5 \times 10^{6}, 5 \times 10^{5}, 5 \times 10^{4}, 5 \times 10^{3}, 5 \times 10^{2}$ and 0 copies $/ \mathrm{ml}$ ). After incubation of $12 \mathrm{~h}$, the cell cycle was detected with an FITC BrdU Flow kit (BD Pharmingen) according to the manufacturer's instructions. Briefly, the pretreated LX-2 cells were labeled with BrdU for $45 \mathrm{~min}$, washed, and fixed and permeabilized with BD Cytofix/Cytoperm buffer. After repeated incubation on ice, washed and centrifugated cells were treated with DNase to expose BrdU epitope for $1 \mathrm{~h}$ at $37^{\circ} \mathrm{C}$, The cells were washed and stained with fluorescent anti-BrdU for $20 \mathrm{~min}$ at room temperature, washed again and centrifugated. Staining buffer containing 7-Aminoactinomycin D (7-AAD) ( $1 \mathrm{ml}$; BD Pharmingen) was added to each tube to resuspend the cells. Finally, the cells were analyzed by flow cytometry (Becton-Dickinson, San Jose, CA, USA). Acquired multiparameter data were analyzed using CellQuest software. With the combination of BrdU and 7-AAD, 2-color flow cytometric analysis permits the enumeration and characterization of cells that are actively synthesizing DNA (BrdU Incorporation) in terms of their cell cycle position (i.e., G0/1, S or G2/M phases defined by 7-AAD staining intensities). As shown by the region gates applied to the 7-AAD vs. BrdU dot plot, flow cytometric analysis of cells stained with the reagents allowed the discrimination of cell subsets that were in the G0/G1 phase (R3), S-phase (R4), G2+M phase (R5) (21). 
Table I. Primers for real-time PCR.

\begin{tabular}{|c|c|c|}
\hline Gene & Accession & Primer sequence \\
\hline PDGF-B & NM_033016.2 & $\begin{array}{l}\text { F: 5'-tgatctccaacgcctgct-3' } \\
\text { R: 5'-tcatgttcaggtccaactcg-3' }\end{array}$ \\
\hline PDGFR- $\beta$ & NM_002609.3 & $\begin{array}{l}\text { F: 5'-tctgggaccagcagtctttc-3' } \\
\text { R: 5'-cctccaggaagtcctccttac-3' }\end{array}$ \\
\hline$\alpha-S M A$ & NM_001613.2 & $\begin{array}{l}\text { F: 5'-ctgttccagccatccttcat-3' } \\
\text { R: 5'-tcatgatgctgttgtaggtggt-3' }\end{array}$ \\
\hline Collagen-I & NM_000088.3 & $\begin{array}{l}\text { F: 5'-cagcgctggtttcgactt-3' } \\
\text { R: 5'-ccatcgtgagccttctcttg-3' }\end{array}$ \\
\hline GAPDH & NM_002046.3 & $\begin{array}{l}\text { F: 5'-agccacatcgctcagacac-3' } \\
\text { R: 5'-gcccaatacgaccaaatcc-3' }\end{array}$ \\
\hline
\end{tabular}

$\alpha$-SMA, $\alpha$-sooth muscle actin; GAPDH, glyceraldehyde phosphate dehydrogenase; PDGFR- $\beta$, platelet-derived growth factor receptor- $\beta$.F, forward; $\mathrm{R}$, reverse.

Detection of the mRNA of PDGF-B, PDGFR- $\beta, \alpha-S M A$, collagen-I by real-time PCR. Total RNA was extracted with TRIzol (Invitrogen) and was reverse-transcribed by random hexamer primer. Then quantitative real-time PCR analysis was performed using the GeneAmp 7500 system and SYBR ${ }^{\circledR}$ Green (Applied Biosciences). All expression data were normalized to GAPDH. Each reaction contained: $10 \mu \mathrm{l}$ of SYBR-Green, $1 \mu 1$ sense and antisense specific primer respectively and $1 \mu \mathrm{l}$ of cDNA matrix, in a final volume of $20 \mu \mathrm{l}$. All reactions were repeated 3 times. PCR products were obtained after $10 \mathrm{~min}$ at $95^{\circ} \mathrm{C}$, followed by 45 cycles of $10 \mathrm{sec}$ at $95^{\circ} \mathrm{C}, 5 \mathrm{sec}$ at $60^{\circ} \mathrm{C}$ and $10 \mathrm{sec}$ at $72^{\circ} \mathrm{C}$. The primers used for amplification are shown in Table I. The relative quantity of the products was expressed as a fold-induction of the target gene compared with the control primers according to the formula $2^{-\Delta \Delta \mathrm{CT}}(22)$.

Detection of PDGF-BB by ELISA. To quantify the expression levels of PDGF-BB in the co-culture supernatant, ELISA Systems (R\&D Systems) was performed according to the manufacturer's instructions. Ninety-six-well polystyrene microplates were pre-coated with recombinant human PDGFR $\beta /$ Fc chimera and $100 \mu 1$ standard, control and culture supernatant was added to each well. Cells were incubated for $2 \mathrm{~h}$, aspirated and washed 4 times. Then, $200 \mu \mathrm{l}$ of conjugate was added to the cells, incubated for $2 \mathrm{~h}$ and washed 4 times. A $200 \mu \mathrm{l}$ substrate solution was added to each well and the cells were incubated for $30 \mathrm{~min}$. Finally, a stop solution was added to each well and the absorbance at $450 \mathrm{~nm}$ was determined on an ELISA reader. We repeated the experiment 3 times.

Western blotting. To detect the expression of PDGFR- $\beta$, and phos-PDGFR- $\beta$, LX-2 cells were lysed in RIPA lysis buffer (50 mmol/1 Tris- $\mathrm{HCl}$ ( $\mathrm{pH} 7.4$ ), 1\% NP-40, 0.25\% sodium deoxycholate, $150 \mathrm{mmol} / 1 \mathrm{NaCl}, 0.1 \%$ SDS, $1 \mathrm{mmol} / \mathrm{l}$ EDTA, $1 \mathrm{mmol} / 1 \mathrm{PMSF}, 1 \mathrm{mmol} / 1 \mathrm{Na}_{3} \mathrm{VO}_{4}$, and $1 \mathrm{mmol} / 1 \mathrm{NaF}$ ). Protein concentrations were determined using the Bio-Rad protein assay kit (Bio-Rad, Hercules, CA USA). After boiling for $5 \mathrm{~min}$, the lysate were separated on $10 \%$ SDS-PAGE polyacrylamide gel. Proteins were transferred to nitrocellulose membranes which were blocked in Tris-buffered saline with Tween-20 (TTBS) containing 5\% non-fat dried milk. The membranes were incubated with primary antibody against PDGFR- $\beta$, or phospho-PDGFR- $\beta$ and $\beta$-actin at $4^{\circ} \mathrm{C}$ overnight. After rinsing three times in TTBS, the membranes were incubated with secondary antibody conjugated with horseradish peroxidase (HRP) at room temperature for $1 \mathrm{~h}$ and then developed using a chemiluminescence detection kit (Amersham Biosciences), according to the manufacturer's instructions and exposed to X-ray film. The relative expression of these proteins was determined by densitometric scanning and calculating the ratios of each protein to $\beta$-actin bands, which were expressed constitutively.

Statistical analysis. Statistical analysis of the results was performed by one-way ANOVA, the Newman-Keuls test, the Mann-Whitney test, and the unpaired Student's t-test when appropriate. Differences were considered to be significant at $\mathrm{P}<0.05$.

\section{Results}

Proliferation of LX-2 cells after incubation with $H B V$ or viral proteins. The cell cycle was analyzed by using BrdU and 7-AAD to measure the proliferation of LX-2 cells stimulated by $\mathrm{HBV}$ or viral proteins. After incubation with $\mathrm{HBV}$, the cell number in S-phase of LX-2 cells increased with different concentrations of HBV (Fig. 1 and Table IIA). The proliferation rate of LX-2, stimulated with $5 \times 10^{4}, 5 \times 10^{5}$ and $5 \times 10^{6} \mathrm{copies} / \mathrm{ml} \mathrm{HBV}$, was $30.42 \pm 1.58 \%, 34.12 \pm 2.35 \%$ and $35.11 \pm 2.05 \%$, respectively. HBV had a significant effect on the cell proliferation as compared with that of 0 copies $/ \mathrm{ml}$ of HBV $(25.50 \pm 2.98 \%, \mathrm{P}<0.05)$, indicating that HBV particles promote LX-2 proliferation in a dose-dependent pattern 

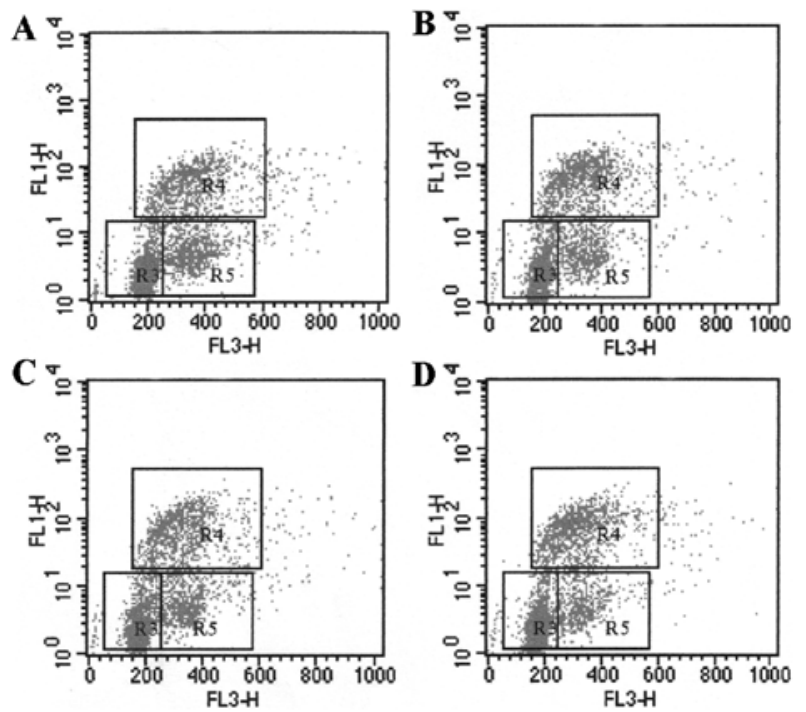

Figure 1. Proliferation of LX-2 cells after incubation with HBV. LX-2 cells cultured in complete medium for $24 \mathrm{~h}$ were serum starved for $16 \mathrm{~h}$. Incubation followed with (A) 0 copies $/ \mathrm{ml}$, (B) $5 \times 10^{4}$ copies $/ \mathrm{ml}$, (C) $5 \times 10^{5}$ copies $/ \mathrm{ml}$, (D) $5 \times 10^{6}$ copies/ml of HBV for $12 \mathrm{~h}$ and the cell cycle of LX-2 was detected with a BrdU Flow kit. Flow cytometric analysis of cells stained with the reagents provided in the kit allowed for the discrimination of cell subsets that were G0/G1 phase (R3), S-phase (R4) amd G2+M phase (R5). The results of FITC dot plots and the proportions of S-phase (R4) cells represented the proliferation of LX-2.
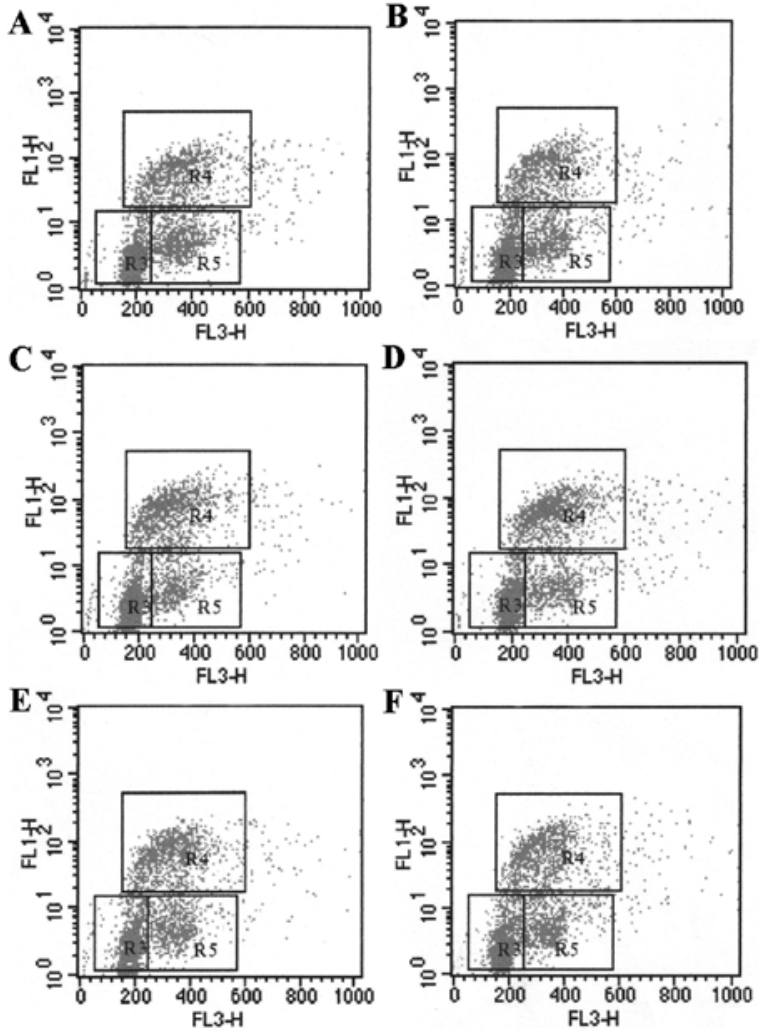

Figure 2. Proliferation of LX-2 cells after incubation with HBV proteins. The HepG-s, HepG-x, HepG-c, HepG-e, HepG2.2.15 or HepG-control cell lines co-cultured with LX-2 cells for $48 \mathrm{~h}$, respectively as described in the Materials and methods and then the cell cycle of LX-2 was detected with BrdU Flow kit. The results of FITC dot plots and the proportions of S-phase (R4) cells represented the proliferation of LX-2. (A) Negative control group; (B) LX-2 co-cultured with HepG-s cells; (C) LX-2 co-cultured with HepG-X cells; (D) LX-2 co-cultured with HepG-c cells; (E) LX-2 co-cultured with HepG-e cells and (F) LX-2 co-cultured with HepG-2.2.15 cells.
Table II. Proliferation of LX-2 cells after incubation with HBV.

A, Proliferation of LX-2 cells after incubation with $\operatorname{HBV}(n=5)$

Concentration of

HBV (copies/ml)

S-phase cell $(\%)$

P-value

0

$25.50 \pm 2.98$

$5 \times 10^{4}$

$5 \times 10^{5}$

$30.42 \pm 1.58$

$5 \times 10^{6}$

$34.12 \pm 2.35$

$<0.05^{\mathrm{a}}$

$35.11 \pm 2.05$

$<0.05^{\mathrm{a}}$

B, Proliferation of LX-2 cells after incubation with HBV proteins $(\mathrm{n}=5)$

Co-culture with

viral protein $\quad$ S-phase cell $(\%) \quad$ P-value

\begin{tabular}{lll}
\hline HepG-control & $25.32 \pm 2.78$ & \\
HepG-s & $25.35 \pm 1.88$ & \\
HepG-e & $26.84 \pm 3.05$ & \\
HepG-c & $35.34 \pm 2.85$ & $<0.05^{\mathrm{b}}$ \\
HepG-x & $36.44 \pm 2.45$ & $<0.05^{\mathrm{b}}$ \\
HepG2.2.15 & $30.94 \pm 2.60$ & $<0.05^{\mathrm{b}}$ \\
\hline
\end{tabular}

${ }^{\mathrm{a}} \mathrm{vs.} 0$ copies/ml HBV group; ${ }^{\mathrm{b}} \mathrm{vs}$. HepG-control group.

(Table IIA). In the co-culture system, the proliferation of LX-2 cells in S-phase significantly increased up to $36.44 \pm 2.45 \%$ and $35.34 \pm 2.85 \%$ after incubation with HepG-x or HepG-c cells, which express $\mathrm{x}$ or $\mathrm{c}$ protein of $\mathrm{HBV}$, compared with HepGcontrol cell $(\mathrm{P}<0.05)$. However, HepG-e and HepG-s had no obvious effect on the LX-2 proliferation. The results indicated that the HBV $\mathrm{x}$ and $\mathrm{c}$ proteins promote LX-2 proliferation (Fig. 2 and Table IIB).

$H B V$ or $H B V$-x or $H B V$-c protein upregulated $m R N A$ levels of Collagen-I, $\alpha$-SMA PDGF-B and PDGFR- $\beta$ in LX-2 cells. After incubation with different concentrations of HBV for $12 \mathrm{~h}$, total mRNA from LX-2 cells was extracted with TRIzol. mRNA levels of collagen-I, $\alpha-S M A$, PDGF-B and PDGFR- $\beta$ were detected by real-time PCR, respectively. The increased mRNA levels of collagen-I and $\alpha$-SMA were observed in $5 \times 10^{5}$ and $5 \times 10^{6}$ copies/ml HBV concentration groups (Fig. 3). Both collagen-I and $\alpha$-SMA showed an increase approximately 2 times greater than that in the control group $(\mathrm{P}<0.05)$. The mRNA levels of PDGF-B and PDGFR- $\beta$ in LX-2 cells were also upregulated significantly in the $5 \times 10^{5}$ and $5 \times 10^{6}$ copies $/ \mathrm{ml}$ groups, compared with the control group $(\mathrm{P}<0.05)$. However, there were no apparent changes in mRNA levels of the parameters mentioned above in $\mathrm{HBV}$ concentration of $5 \times 10^{2}$ $5 \times 10^{4}$ copies/ml (Fig. 3).

Meanwhile, mRNA levels of collagen-I, $\alpha-S M A$, PDGF-B and PDGFR- $\beta$ in LX- 2 cells were also detected by real-time PCR after co-culture with HepG-s, HepG-x, HepG-c, HepG-e, HepG2.2.15 and HepG-control cells, respectively, for $48 \mathrm{~h}$. Increased mRNA levels of collagen-I, $\alpha-S M A$, PDGF-B and 


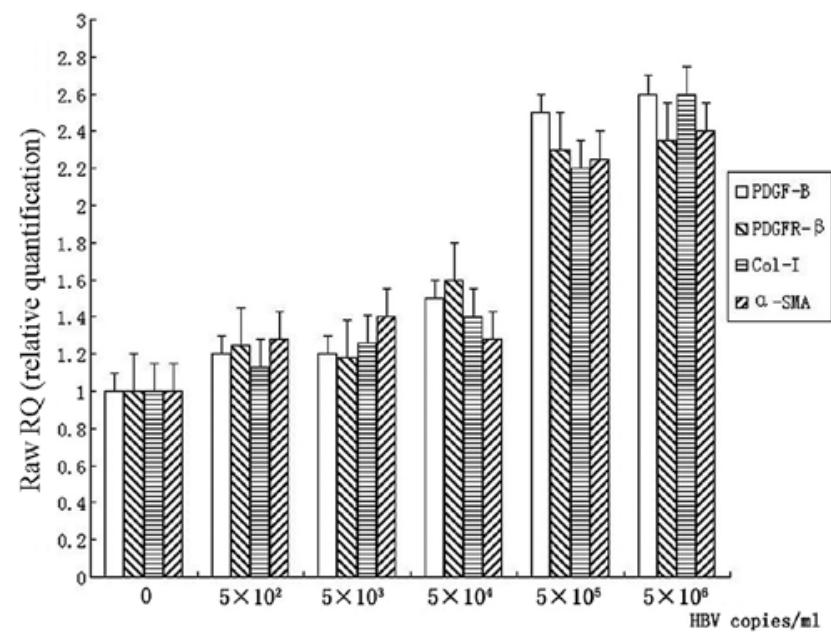

Figure 3. Detection of the mRNA levels of PDGF-B, PDGFR- $\beta$, collagen-I (Col-I) and $\alpha$-SMA in LX- 2 cells. LX-2 cells were cultured in complete medium for $24 \mathrm{~h}$, serum starved for $16 \mathrm{~h}$. Following incubation with $0,5 \times 10^{2}, 5 \times 10^{3}$, $5 \times 10^{4}, 5 \times 10^{5}$ or $5 \times 10^{6}$ copies $/ \mathrm{ml}$ of HBV for $12 \mathrm{~h}$, total mRNA was extracted and mRNA levels of PDGF-B, PDGFR- $\beta$, collagen-I and $\alpha$-SMA were detected by real-time PCR. All the values were normalized to GAPDH $(n=5)$.

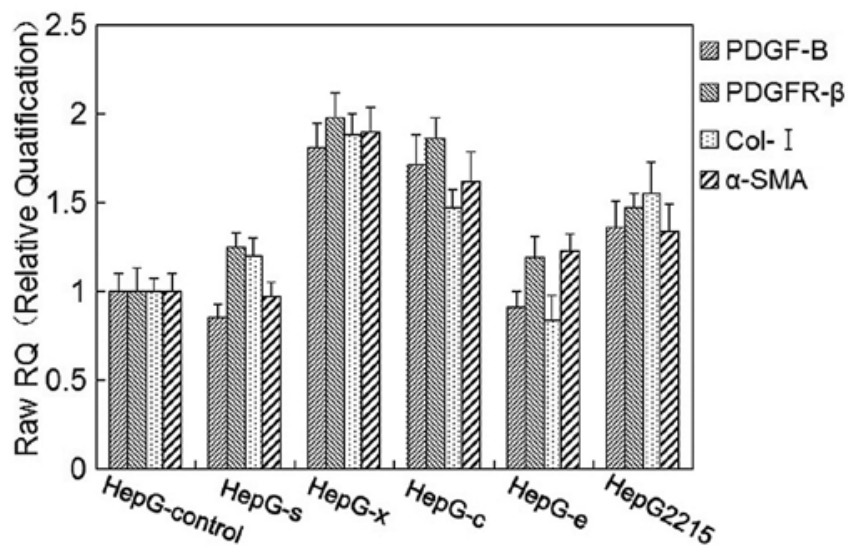

Figure 4. Detection of the mRNA levels of PDGF-B, PDGFR- $\beta$, collagen-I (Col-I) and $\alpha$-SMA in LX-2 cells inoculated with HBV proteins. The HepG-s, HepG-x, HepG-c, HepG-e and HepG2.2.15 cells co-cultured with LX-2 cells respectively for $48 \mathrm{~h}$. Total mRNA was extracted from LX-2 cells. Then the mRNA levels of PDGF-B, PDGFR- $\beta$, collagen-I, $\alpha$-SMA were detected by real-time PCR. All the values were normalized to GAPDH $(n=5)$.

PDGFR- $\beta$ were observed in LX-2 cells after being co-cultured with HepG-x or HepG-c, and they were approximately 1.5-2 times higher than the control group. In co-culture with HepG2.2.15, mRNA levels of collagen-I, $\alpha$-SMA, PDGF-B and PDGFR- $\beta$ in LX- 2 cells slightly increased and there were no significant difference as compared with control group ( $p>0.05$ ) (Fig. 4). There were no effects of HepG-s or HepG-e on mRNA levels of collagen-I, $\alpha$-SMA, PDGF-B and PDGFR- $\beta$ in LX- 2 cells.

$H B V$ or HepG-c or HepG-x upregulated the expression levels of the phos-PDGFR- $\beta$ protein in $L X-2$ cells. After incubation with HBV at concentration of 0 copies $/ \mathrm{ml}, 5 \times 10^{2}$ $5 \times 10^{6}$ copies $/ \mathrm{ml}$ for $12 \mathrm{~h}$ or co-cultured with HepG-s, HepG-x, HepG-c, HepG-e, HepG-control and HepG2.2.15 cells for $48 \mathrm{~h}$,

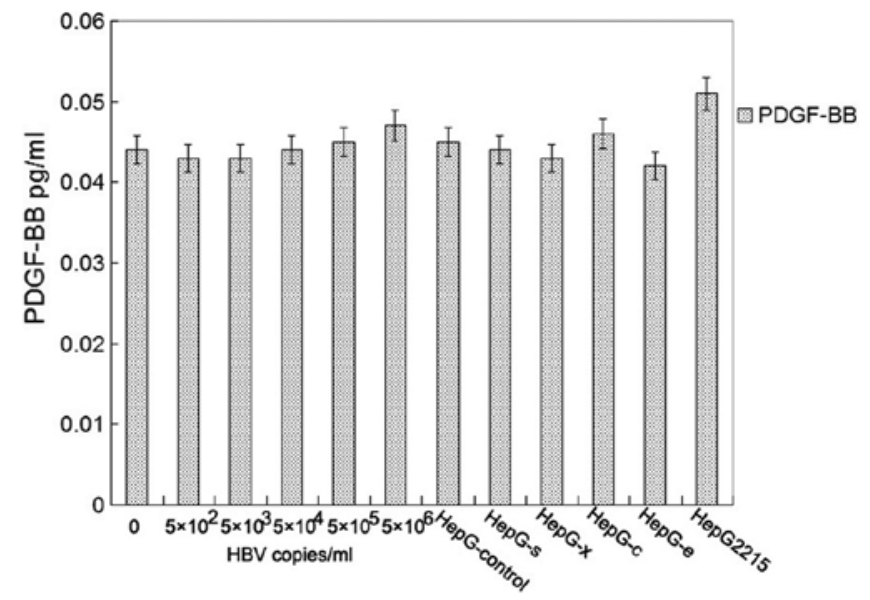

Figure 5. Detection of the PDGF-BB expression in the LX-2 cells by ELISA. After stimulation with HBV particles for $12 \mathrm{~h}$, or co-cultured with the HepGcontrol, HepG-s, HepG-x, HepG-c, HepG-e and HepG2.2.15 cell lines, respectively for $48 \mathrm{~h}$, culture supernatants were collected and concentrated 10 times under a low temperature vacuum. Then PDGF-BB was detected with the ELISA kit $(\mathrm{n}=5)$.
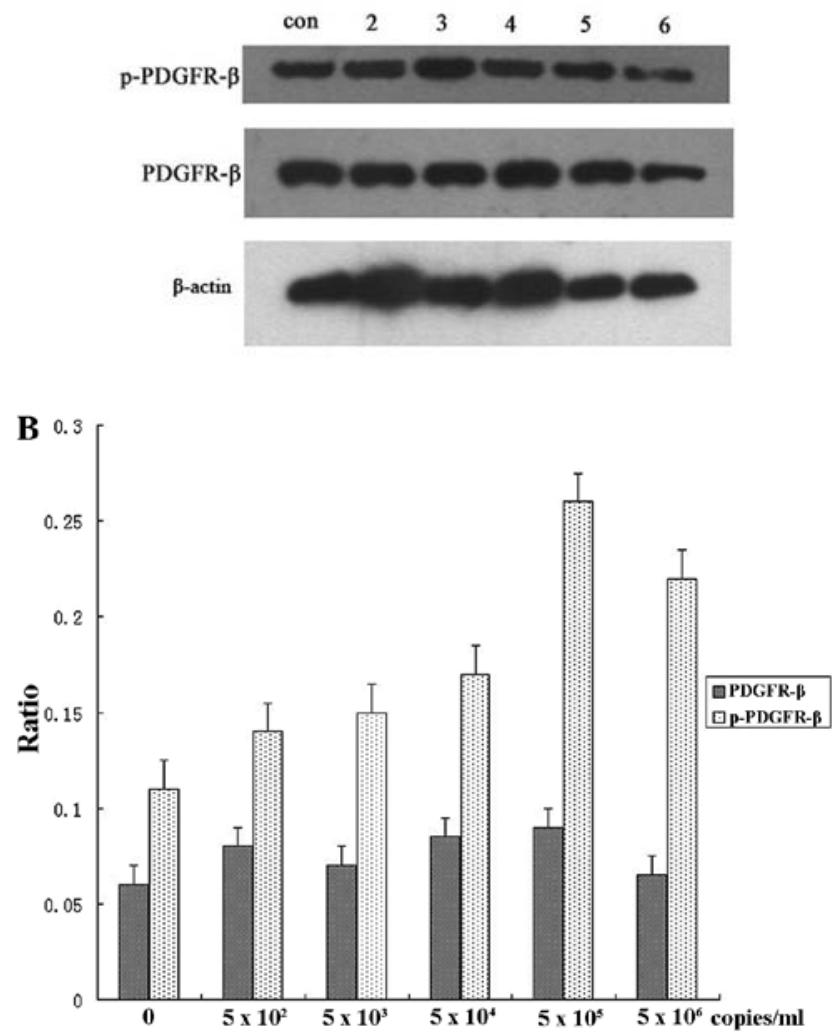

Figure 6. (A) Detection of the expression of PDGFR- $\beta$ and its phosphorylation in LX-2 inoculated with HBV particles by western blotting. (B) LX-2 cells were cultured in complete medium for $24 \mathrm{~h}$, then serum starved for $16 \mathrm{~h}$, added $0,5 \times 10^{2}, 5 \times 10^{3}$ copies $/ \mathrm{ml}, 5 \times 10^{4}, 5 \times 10^{5}$ and $5 \times 10^{6}$ copies $/ \mathrm{ml} \mathrm{HBV}$, and cultured for $12 \mathrm{~h}$. LX- 2 cells were lysed in RIPA lysis buffer. PDGFR- $\beta$ and phos-PDGFR- $\beta$ were detected. All the values were normalized to $\beta$-actin $(n=5)$.

respectively, LX-2 cells were collected for detection PDGFR- $\beta$ and phospho-PDGFR- $\beta$ by western blotting. One milliliter of culture supernatants were collected for detection of PDGF-BB 

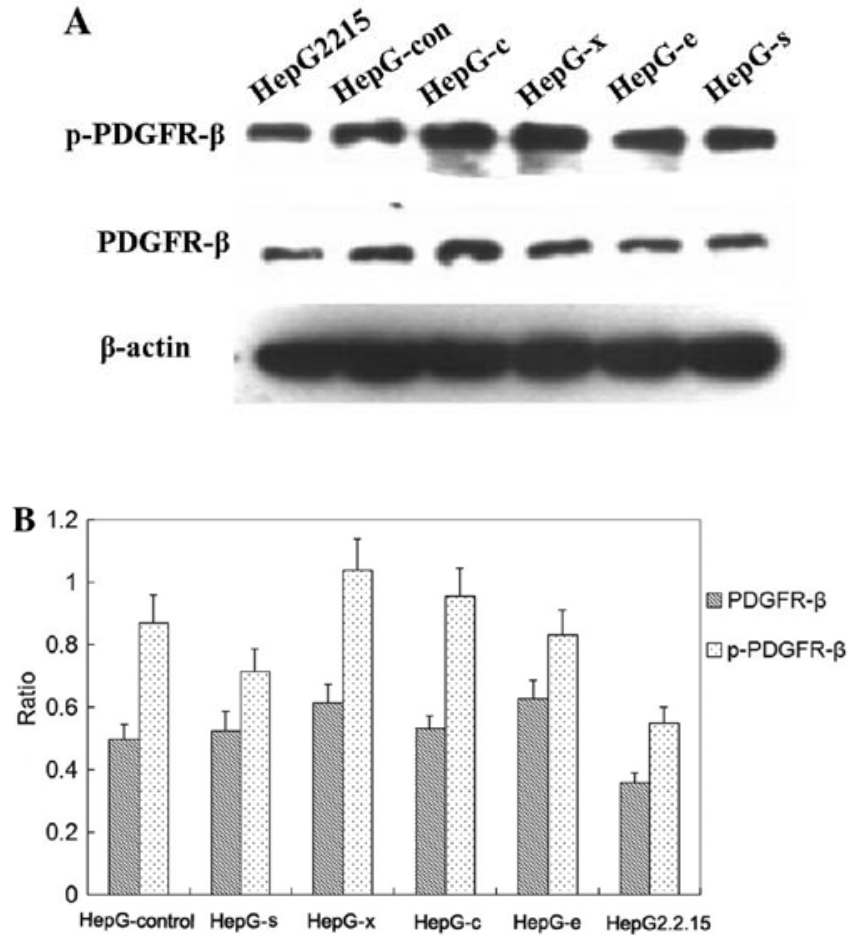

Figure 7. (A) Detection of the expression of PDGFR- $\beta$ and its phosphorylation in LX-2 inoculated with HBV proteins by western blotting. (B) After co-culture with HepG-control, HepG-s, HepG-x, HepG-c, HepG-e and HepG2.2.15 cell line for $48 \mathrm{~h}$, respectively. LX-2 cells were lysed in RIPA lysis buffer, then PDGFR- $\beta$ and phospho-PDGFR- $\beta$ were detceted. All values were normalized to $\beta$-actin $(n=5)$.

by ELISA. Unfortunately, there was no detectable level of PDGF-BB in all of groups (Fig. 5). The relative expression levels of the proteins were determined by densitometric scanning and calculating the ratios of each protein to constitutively expressed $\beta$-actin bands. There were no changes in PDGFR- $\beta$ levels after treatment with any concentration of HBV or viral protein (Figs. 6 and 7). However, phosphorylation activity of PDGFR- $\beta$ in LX- 2 cells was increased after treatment with HBV and the peak value was observed in group of $5 \times 10^{5}$ copies $/ \mathrm{ml}$ HBV (Fig. 6) $(\mathrm{P}<0.05)$. Treatment with viral protein of HBV-c or HBV-x could also upregulated the level of phospho-PDGFR- $\beta$ in LX-2 cells (Fig. 7) $(\mathrm{P}<0.05)$.

\section{Discussion}

$H B V$ Dane particles, $H B V$ protein c and $x$, not e or s, promote HSCs proliferation. Chronic HBV infection has been recognized to exacerbate liver fibrosis in patients. However, HSCs, activated by a variety of host factors and/or viral proteins, is considered to be the most important contributor to fibrosis progression and has been investigated intensively. Generally, the activation process of HSCs includes a loss of vitamin A droplets, an increased proliferation rate, a phenotypic transition to a myofibroblast-like, $\alpha$-SMA positive cell and a dramatic increase in the synthesis of extracellular matrix proteins. Activated HSCs are the major collagen producing cells during hepatic fibrogenesis. Although chronic HBV infection is one of the major causes of liver fibrosis, the HBV-specific steps in
HSCs proliferation and pathogenesis of liver fibrosis remain unclear. In our previous study, it was found that supernatants from the HepG2.2.15 culture could promote LX-2 cell proliferation (23); however, the possible role of $\mathrm{HBV}$ viral particles or HBV proteins in the development of liver fibrosis remains unclear. It is necessary to identify which factors of HBV are involved in the activation of HSCs. Thus the activation of HSCs followed by HBV stimulation was characterized in the present study.

To explore the direct interaction between HBV and HSCs, purified HBV particles were obtained from the supernatants of HepG2.2.15 cells cultured by sucrose density gradient ultracentrifugation and plasmids expressing HBV proteins were constructed. The roles of $\mathrm{HBV}$ or the viral proteins on the LX-2 cells proliferation were investigated with the co-cuture system. We found that the cell number in S-phase of LX-2 cells was upregulated after HBV incubation in a dose-dependent manner, and the peak value was observed at $5 \times 10^{6}$ copies/ml HBV (Fig. 1 and Table 2A). Moreover, the cell number in S-phase of LX-2 cells also increased after co-culture with HepG2 cells which were transfected with plasmids pHBV-C and $\mathrm{pHBV}-\mathrm{X}$, but not pHBV-E or pHBV-S (Fig. 2 and Table IIB). As we mentioned above, HSCs convert into proliferating $\alpha$-SMA-expressing and collagen-producing cells after a fibrogenic stimulus. Thus, the mRNA levels of $\alpha$-SMA and collagen-I were further detected, and showed an increase approximately 2 times greater than those in the control group with the concentration of $5 \times 10^{6}$ copies/ml (Fig. 3). Similarily, $\alpha$-SMA and collagen-I mRNA levels were also detected in the LX-2 cells co-cultured with HepG-c and HepG-x (Fig. 4). The results mentioned above indicated that HBV Dane particles, as well as the HBV viral protein $\mathrm{c}$ or $\mathrm{x}$ could promote LX-2 proliferation, which was characterized with the increased proliferation rate and metabolic changes.

Our results were consistent with other studies which have reported that HCV viral proteins could directly induce HSC proliferation and release inflammatory cytokines. Treatment with a conditioned medium from Huh-7 cells expressing an HCV core protein (24) or recombinant core protein (25), led to the upregulation of $\alpha$-SMA and other cytokines in LX-2 cells. Moreover, it was reported that the HBV x protein may lead to a paracrine activation and proliferation of HSCs (13). These data show that the viral protein may be able to stimulate HSCs into an active status; however, the intracellular signaling mechanisms of activation and perpetuation are under active investigation.

The PDGF signal pathway involved in the activation of HSCs. During liver fibrosis, activated HSCs proliferate and deposit ECM proteins, a process that is driven by an array of cytokines and growth factors. PDGF has been identified as the most potent mitogen for HSCs, making it an attractive therapeutic target for the treatment of liver fibrosis $(26,27)$. Marra et al (8) have also demonstrated how HSCs perpetuate their proliferative status by active secretion of PDGF in an autocrine or paracrine manner. Moreover, PDGF receptors (PFGFR) are highly upregulated on the cell surface of activated HSCs during fibrosis (7). Of the PDGF ligand/receptor systems, PDGF-BB signaling through PDGFR- $\beta$ is an important 
mediator in the initiation and progression of liver fibrosis (28). Interestingly, the PDGF-B protein overexpression in the livers of transgenic mice was associated with an increased number of $\alpha$-SMA-positive cells and was also marked by an increase in the PDGFR- $\beta$ transcription (6). Thus, in order to investigate the mechanisms of the proliferation of HSCs caused by HBV infection, we address the role of paracrine PDGF-B/PDGFR- $\beta$ signaling further.

We detected the mRNA and protein levels of PDGF-B and PDGFR- $\beta$ from the LX-2 cells, respectively. The PDGF-B mRNA in LX-2 cells inoculated with HBV particles was upregulated in a dose-dependent manner and the highest level was observed in the $5 \times 10^{6} \mathrm{HBV}$ copies/ml group (Fig. 3). Subsequently, a co-culture system was used to detect the effects of viral proteins on LX-2 cells. We found that the HBV $\mathrm{c}$ and $\mathrm{x}$ antigen but not the large $\mathrm{s}$ or e antigen promote the expression of PDGF-B mRNA in LX-2 cells (Fig. 4). We did not detect the expression of PDGF-BB by ELISA. Similarly, the mRNA and phosphorylation level, not the protein level of PDGFR- $\beta$ was also upregulated when stimulated with HBV particles or HBV $\mathrm{c}$ and $\mathrm{x}$. Our results indicated that the HBV particles or virus proteins did not promote the protein expression of PDGF-BB and PDGFR- $\beta$, but the phosphorylation of PDGFR- $\beta$ was upregulated, which indicated the activation of PDGFR. Collectively, HSC proliferation mediated by HBV or viral proteins via PDGFR- $\beta$ phosphorylation and the subsequent activation of the PDGF-BB signal pathway.

Several studies provide ample evidence of the PDGF-B/ PDGFR- $\beta$ pathway being a strong stimulus of HSC proliferation, which may be attenuated by anti-PDGF strategies. For example, the tyrosine kinase inhibitor AG 1295 of PDGF inhibit HSCs proliferation through reducing the phosphorylation of PDGFR- $\beta$ and the downstream signaling molecules ERK1/2 and Akt (29). Administration of A771726, metabolite of leflunomide, markedly blunted the PDGFR- $\beta$ expression and phosphorylation in activated HSCs (30). Moreover, in culture-activated HSCs, a soluble PDGF-B receptor was able to block the phosphorylation of endogenous PDGF receptors and reduce the proliferative activity of HSCs (31).

In conclusion, our data suggest that HBV Dane particles, $\mathrm{x}$ and $\mathrm{c}$ protein may induce HSCs proliferation through effecting on PDGF-B/PDGFR- $\beta$ signal pathway which play an important role of in liver fibrosis caused by HBV infection. HBV Dane particles and $\mathrm{x}$ and $\mathrm{c}$ protein may upregulate the mRNA levels of PDGF-B and PDGFR- $\beta$ and promote the phosphorylation of PDGFR- $\beta$, leading to the later auto-phosphorylation. Therefore, interference with PDGF-B/PDGFR- $\beta$ signal pathway may be a potential target for antifibrotic therapies in liver disease.

\section{Acknowledgements}

We thank Dr Lijun Zhang and Dr Xia Peng (School of Public Health, Fudan University) for their assistance and comments during this study. This study was supported by the National Natural Science Foundation of China (no. 30671854), the National High Technology Research and Development Program of China (863 Program, no. 2006AA02A410) and the Major State Basic Research Development Program of China (973 Program, no. 2007CB512802).

\section{References}

1. Gutierrez-Reyes G, Gutierrez-Ruiz MC and Kershenobich D: Liver fibrosis and chronic viral hepatitis. Arch Med Res 38: 644-651, 2007.

2. Breitkopf K, Roeyen C, Sawitza I, Wickert L, Floege J and Gressner AM: Expression patterns of PDGF-A, -B, -C and -D and the PDGF-receptors alpha and beta in activated rat hepatic stellate cells (HSC). Cytokine 31: 349-357, 2005.

3. Pinzani M, Milani S, Herbst H, et al: Expression of plateletderived growth factor and its receptors in normal human liver and during active hepatic fibrogenesis. Am J Pathol 148: 785-800, 1996.

4. Pinzani M: PDGF and signal transduction in hepatic stellate cells. Front Biosci 7: d1720-d1726, 2002.

5. Marra F, Pinzani M, DeFranco R, Laffi G and Gentilini P: Involvement of phosphatidylinositol 3-kinase in the activation of extracellular signal-regulated kinase by PDGF in hepatic stellate cells. FEBS Lett 376: 141-145, 1995.

6. Czochra P, Klopcic B, Meyer E, et al: Liver fibrosis induced by hepatic overexpression of PDGF-B in transgenic mice. J Hepatol 45: 419-428, 2006

7. Pinzani M, Gesualdo L, Sabbah GM and Abboud HE: Effects of platelet-derived growth factor and other polypeptide mitogens on DNA synthesis and growth of cultured rat liver fat-storing cells. J Clin Invest 84: 1786-1793, 1989.

8. Marra F, Choudhury GG, Pinzani M and Abboud HE: Regulation of platelet-derived growth factor secretion and gene expression in human liver fat-storing cells. Gastroenterology 107: 1110-1117, 1994.

9. Lehti K, Allen E, Birkedal-Hansen H, et al: An MT1-MMPPDGF receptor-beta axis regulates mural cell investment of the microvasculature. Genes Dev 19: 979-991, 2005.

10. Lindahl P, Hellstrom M, Kalen M, et al: Paracrine PDGF-B/ PDGF-Rbeta signaling controls mesangial cell development in kidney glomeruli. Development 125: 3313-3322, 1998.

11. Feitelson MA, Reis HM, Tufan NL, Sun B, Pan J and Lian Z: Putative roles of hepatitis $\mathrm{B} x$ antigen in the pathogenesis of chronic liver disease. Cancer Lett 286: 69-79, 2009.

12. Guo GH, Tan DM, Zhu PA and Liu F: Hepatitis B virus X protein promotes proliferation and upregulates TGF-betal and CTGF in human hepatic stellate cell line, LX-2. Hepatobiliary Pancreat Dis Int 8: 59-64, 2009.

13. Martin-Vilchez S, Sanz-Cameno P, Rodriguez-Munoz Y, et al: The hepatitis $B$ virus $X$ protein induces paracrine activation of human hepatic stellate cells. Hepatology 47: 1872-1883, 2008.

14. Lou SM, Li YM, Wang KM, Cai WM and Weng HL: Expression of platelet-derived growth factor-BB in liver tissues of patients with chronic hepatitis B. World J Gastroenterol 10: 385-388, 2004.

15. Cai WM, Zhang BB, Weng HL, et al: The diagnostic value of eight serum indices for liver fibrosis. Zhonghua Gan Zang Bing Za Zhi 12: 219-222, 2004 (In Chinese).

16. Zhang BB, Cai WM, Weng HL, et al: Diagnostic value of platelet derived growth factor-BB, transforming growth factorbeta1, matrix metalloproteinase-1, and tissue inhibitor of matrix metalloproteinase- 1 in serum and peripheral blood mononuclear cells for hepatic fibrosis. World J Gastroenterol 9: 2490-2496, 2003.

17. Seifer M, Heermann KH and Gerlich WH: Replication of hepatitis B virus in transfected nonhepatic cells. Virology 179: 300-311, 1990.

18. Pan XB, Han JC, Gao Y and Wei L: High replicated hepatitis B virus induces apoptosis of hepatocytes. Zhonghua Yi Xue Za Zhi 88: 840-843, 2008 (In Chinese).

19. Gao N, Chen W, Zheng Q, et al: Co-expression of Japanese encephalitis virus prM-E-NS1 antigen with granulocytemacrophage colony-stimulating factor enhances humoral and anti-virus immunity after DNA vaccination. Immunol Lett 129: 23-31, 2010.

20. Hintermann E, Bayer M, Pfeilschifter JM, Luster AD and Christen U: CXCL10 promotes liver fibrosis by prevention of NK cell mediated hepatic stellate cell inactivation. J Autoimmun 35: 424-435, 2010.

21. Kitagawa J, Hara T, Tsurumi H, et al: Cell cycle-dependent priming action of granulocyte colony-stimulating factor (G-CSF) enhances in vitro apoptosis induction by cytarabine and etoposide in leukemia cell lines. J Clin Exp Hematop 50: 99-105, 2010. 
22. Melgar-Lesmes P, Casals G, Pauta M, et al: Apelin mediates the induction of profibrogenic genes in human hepatic stellate cells. Endocrinology 151: 5306-5314, 2010.

23. Liu X, Zhu ST, You H, et al: Hepatitis B virus infects hepatic stellate cells and affects their proliferation and expression of collagen type I. Chin Med J (Engl) 122: 1455-1461, 2009.

24. Clement S, Pascarella S, Conzelmann S, Gonelle-Gispert C, Guilloux K and Negro F: The hepatitis $C$ virus core protein indirectly induces alpha-smooth muscle actin expression in hepatic stellate cells via interleukin-8. J Hepatol 52: 635-643, 2010.

25. Coenen M, Nischalke HD, Kramer B, et al: Hepatitis C virus core protein induces fibrogenic actions of hepatic stellate cells via toll-like receptor 2. Lab Invest 91: 1375-1382, 2011.

26. Gonzalo T, Beljaars L, van de Bovenkamp M, et al: Local inhibition of liver fibrosis by specific delivery of a plateletderived growth factor kinase inhibitor to hepatic stellate cells. J Pharmacol Exp Ther 321: 856-865, 2007.
27. Ogawa S, Ochi T, Shimada H, et al: Anti-PDGF-B monoclonal antibody reduces liver fibrosis development. Hepatol Res 40: $1128-1141,2010$

28. Borkham-Kamphorst E, van Roeyen CR, Ostendorf T, Floege J, Gressner AM and Weiskirchen R: Pro-fibrogenic potential of PDGF-D in liver fibrosis. J Hepatol 46: 1064-1074, 2007.

29. Iwamoto H, Nakamuta M, Tada S, Sugimoto R, Enjoji M and Nawata H: Platelet-derived growth factor receptor tyrosine kinase inhibitor AG1295 attenuates rat hepatic stellate cell growth. J Lab Clin Med 135: 406-412, 2000.

30. Si HF, Lv X, Guo A, Jiang H and Li J: Suppressive effect of leflunomide on rat hepatic stellate cell proliferation involves on PDGF-BB-elicited activation of three mitogen-activated protein kinases. Cytokine 42: 24-31, 2008.

31. Kinnman N, Francoz C, Barbu V, et al: The myofibroblastic conversion of peribiliary fibrogenic cells distinct from hepatic stellate cells is stimulated by platelet-derived growth factor during liver fibrogenesis. Lab Invest 83: 163-173, 2003. 